\title{
Theodōros Metochitēs
}

* I270 in Konstantinopel (Istanbul,Türkei)

† I3. März I332 in Konstantinopel (Istanbul, Türkei)

Sohn des Pro-Unionisten Geōrgios Metochitēs; trat I29o in den Dienst des überzeugt orthodoxen Kaisers Andronikos II. Palaiologos (I282I328); ab ca. I295 Logothetēs tu geniku (Finanzminister); stieg I32I zum Megas logothetēs (Kanzler) auf; Exil nach dem Sturz Andronikos' I328; um I330 Rückkehr nach Konstantinopel.

\section{Memoranden und Sentenzen / Hypomnēmatismoi kai sēmeiōseis gnōmikai}

Die um 1326 entstandene Sammlung von I20 Essays nimmt in der rhetorischen Produktion der Byzantiner einen herausragenden Platz ein. Eröffnet wird die Sammlung mit der berühmten Aporie, dass es für die Nachgeborenen (= Byzantiner) unmöglich sei, angesichts des klassischen Erbes etwas Neues zu sagen. Die Neufassung altbekannten Materials solle daher Metochitēs' literarischen Charakter (ēthos) demonstrieren. Die Pflege seiner Schriften für die Nachwelt wurde dem Adlatus Nikephoros Grēgoras in der Bibliothek des von Metochitēs restaurierten Chora-Klosters übertragen.

Die Essays lassen sich verschiedenen Themenkreisen zuordnen. Jeweils etwa 20 Essays beschäftigen sich mit dem Werk und vor allem auch dem Stil (»Charakter«) klassischer Autoren, den Bedingungen menschlichen Wissens sowie Aspekten der antiken griechischen und römischen Geschichte und Historiographie. Die anderen 60 behandeln moralische und politische Fragen im weitesten Sinne und nehmen nicht selten auf die Karriere des Metochitēs Bezug, vor allem im Zusammenhang mit Schicksal und Neid, wovon Metochitēs sich zeitlebens verfolgt fühlte. Vorbild der Sammlung dürften die Moralia Plutarchs sein, die Maximos Planudes Ende des I3. Jh.s erstmals als Corpus zusammenführte; Metochitēs weist sich als großer Bewunderer des kaiserzeitlichen Philosophen aus (Essay 7I). Während sich manche der Essays zeitgenössischen Themen widmen, etwa dem Verfall des byzantinischen Reiches (Essays 37-40), sind die Informationen über das byzantinische Leben im frühen I4. Jh. gering. NIELS GAUL 